\title{
Improving the Properties of Magnesium Alloys for High Temperature Applications
}

\author{
Kaveh Meshinchi Asl \\ School of Materials Science and Engineering, \\ Clemson University, Clemson
}

USA

\section{Introduction}

The demand to reduce the weight of components especially in automotive and aerospace industries has triggered renewed interest in magnesium alloys as a lightweight structural material. Magnesium which is a third lighter than aluminium is the lightest of the structural metals and is used in a diverse range of applications. This is because of their low density, high specific strength and stiffness, superior damping capacity, good electromagnetic shielding characteristics and good machinability [Khomamizadeh et al., 2005; Meshinchi Asl et al., 2009 (a); Mordike \& Ebert 2001; Meshinchi Asl et al., 2009 (b)]. However, the number of commercially available magnesium alloys is still limited especially for applications at elevated temperatures. Increased applications of magnesium alloys for elevated temperature service require the development of low-cost alloys with good creep resistance and sufficiently high strength. The magnesium alloy that has received most attention is AZ91 (Mg-9Al-1Zn, wt.\%) which is being used in approximately $90 \%$ of all magnesium cast products. While this alloy exhibits adequate tensile yield strengths at ambient temperature, it faces strong challenges such as fatigue and creep resistance and also strength at elevated temperatures [Gao et al., 2005; Wang et al., 2003; Meshinchi Asl et al., 2010; Kang et al., 2005].

Studies to understand the reasons for the poor mechanical behaviour of die cast $\mathrm{Mg}-\mathrm{Al}$ alloys at elevated temperatures have focused on the near grain boundary regions where non-equilibrium interdendritic solidification produces a divorced eutectic microstructure of $\mathrm{Mg}_{17} \mathrm{Al}_{12}$ and magnesium. Recent studies have shown that discontinuous precipitation of the $\mathrm{Mg}_{17} \mathrm{Al}_{12}(\beta)$ intermetallic at elevated temperatures is more likely responsible for poor creep properties of these alloys [Moreno et al., 2003].

Considerable efforts have been made in recent years to improve the creep resistance of the $\mathrm{Mg}$-Al based alloys via further alloying additions and the formation of thermally stable precipitates along grain boundaries to resist the deformation by grain boundary sliding. This limitation is attributed to the intermetallic phase $\mathrm{Mg}_{17} \mathrm{Al}_{12}$ under high temperatures. The alloys of Mg-Al-RE (Rare Earth) have been developed recently. Some studies were based on single RE elements but in this research Rare Earths were added as misch metal (MM). This is because Rare Earth elements have the similar behaviour and it is very economical to use misch metals instead of pure rare earths. In the present work the effects of 
Rare Earth addition and aging heat treatment on the microstructure, mechanical properties and creep resistance of AZ91-RE magnesium alloys will be investigated. The effects of Si additions and $\mathrm{Al}$ content on the microstructure, some mechanical properties and creep resistance on magnesium alloys will also be discussed as another solution to produce high temperature resistance magnesium alloys.

As discussed before, magnesium alloys offer lightweight alternatives to conventional metallic alloys because of their low density. However in certain applications, lightweight alloys are subjected to sliding motion, thus wear resistance is becoming a key factor in these alloys. For critical automobile applications, wear properties of magnesium alloys are important. Despite the attractive range of bulk mechanical properties, a relatively poor resistance to fracture and wear is a serious hindrance against wider application of $\mathrm{Mg}$ alloys [Mehta et al., 2004]. Wear resistance can generally be enhanced by introducing a secondary phase(s) to the matrix material. In this fashion, the wear properties can be varied substantially through changes in the microstructure, the morphology, volume fraction and mechanical properties of the reinforcing phase, and the nature of the interface between matrix and reinforcement [Sharma et al., 2000; Lim et al., 2003; Oakley et al., 1995; Alahelistan \& Bergamon, 1993; Lim et al., 2005]. Chen and Alpas (2000) performed testes on AZ91 magnesium alloy, reported a transition from mild to severe wear controlled by a critical surface temperature $347 \mathrm{~K}$ above which severe wear occurred. They observed oxidation and delamination wear mechanisms in the mild wear regime...Lim et al. (2005) investigated the wear behaviour of $\mathrm{Mg}$ - $\mathrm{Al}$ alloy based composite reinforced with $\mathrm{SiC}$ particulates at various loads and speeds. They identified five different wear mechanisms operating singly or with others: abrasion, oxidation, delamination, adhesion, thermal softening and melting. More recently, Lim et al. (2005) experimented the nano-sizaed alumina reinforced magnesium-based composites. In these composites, increasing the reinforcing material up to $1.11 \mathrm{vol} \%$ improved the wear resistance to 1.8 times relative to pure magnesium. Since the Rare Earths are added to the Mg alloys to improve the high temperature properties, it is essential to investigate the effect of Rare Earth content on the wear behaviour of AZ91 magnesium alloy.

\section{Experimental details}

Commercial pure magnesium, Aluminum and zinc (>99.9\%) were used to prepare AZ91 alloy. Manganese was added as Al-25\%Mn master alloy. Alloy was melted in a mild steel crucible and during the melting process, surface of the charge and the melt were protected by Magrex 36 flux. The RE was added to the melt at $750^{\circ} \mathrm{C}$. The melt was held at $750^{\circ} \mathrm{C}$ for 30 min to make sure that the RE could be completely dissolved.

Rare earth elements (REs) were added by means of misch metal (MM) with nominal composition of 50\% Cerium, 25\% Lanthanum, 18\% Neodymium and 7\% Praseodymium. The reason of using misch metal instead of pure elements is the similar behavior of RE elements while it is very economical to use misch metals instead of pure rare earths. The melt was then held at $750^{\circ} \mathrm{C}$ for $30 \mathrm{~min}$ to dissolve RE completely.

Finally the melt was stirred for 3 minutes (for oxide reduction) and after complete defluxing, it was poured at the pouring temperature of $750^{\circ} \mathrm{C}$ into a permanent mold from mild steel which was preheated up to $300^{\circ} \mathrm{C}$. The chemical composition of the samples was determined by wet chemical analysis as shown in Table 1 . 
Metallographic samples were prepared by mounting them in cold setting resin. They were etched in $2 \%$ Nital aqueous solutions for 20 seconds. The microstructure and phase distribution was characterized by Olympus PME3 optical microscopy and Philips XL 40 scanning electron microscope (SEM). The elemental contents of various phases in the polished samples were determined by the energy dispersive X-ray spectroscopy (EDS) system of SEM. Tensile properties of samples were measured (ASTM-B557M standard) using an Instron 4400 at room and $140{ }^{\circ} \mathrm{C}$ temperatures $(1 \mathrm{~mm} / \mathrm{min}$ strain rate). The hardness was measured using Instron Brinell hardness tester. The averages of three measurements were reported for each experiment. For all the samples tested in this investigation, the samples were cut from the same place of the cast ingot and had the same microstructure in terms of grain size and precipitate distribution. Creep tests were performed in air using a creep test machine (ASTM-E139 standard). By plotting the displacement at various times which was measured using a strain gauge, the strain curves were obtained and the steady state strain rate was calculated.

\begin{tabular}{ccccccc} 
Alloy code & Al & Zn & Mn & RE & Si & Mg \\
\hline 1 & 9.20 & 0.90 & 0.25 & - & - & Rem. \\
\hline 2 & 8.90 & 0.85 & 0.30 & 1 & - & Rem. \\
\hline 3 & 9.10 & 0.90 & 0.25 & 2 & - & Rem. \\
\hline 4 & 4.10 & 0.90 & 0.25 & 2 & - & Rem. \\
\hline 5 & 9.00 & 0.80 & 0.3 & 3 & - & Rem. \\
\hline 6 & 8.95 & 0.85 & 0.30 & - & 0.25 & Rem. \\
\hline 7 & 9.00 & 0.91 & 0.25 & - & 0.5 & Rem. \\
\hline 8 & 9.10 & 0.90 & 0.30 & - & 1 & Rem. \\
\hline 9 & 8.90 & 0.85 & 0.25 & - & 2 & Rem.
\end{tabular}

Table 1. Chemical compositions of the samples investigated in wt. \%.

Dry sliding wear test without lubricant according to ASTM G99 was conducted using a pinon-disk apparatus. Pin specimens of diameter $5 \mathrm{~mm}$ and length $15 \mathrm{~mm}$ were prepared by machining of rods that followed out grinding up to 1200-grit silicon carbide, polishing with $0.05 \mu \mathrm{m}$ diamond paste and alcohol and then cleaning with ultrasonic equipment in pure acetone. M35 hardened tool steel of $160 \mathrm{~mm}$ diameter and $65 \mathrm{HRc}$ hardness was used as a counterface. After each test the disc surface was ground against 1200-grit SiC paper and cleaned with acetone. The experiments were performed under various stationary normal loads, sliding speeds and sliding distances. Weight loss values were determined from weight differences before and after the tests using a precise electronic balance with an accuracy of $\pm 0.1 \mathrm{mg}$. Weight loss versus sliding distance curves were plotted and the wear rates were calculated. Frictional force was recorded for each test. In addition, contact surface temperature was detected with a sensitive thermocouple probe that placed in a narrow scratch in side with the axes of the pin. Throughout the tests, thermocouple connection with contact surface was controlled. Temperature against sliding distance curves also plotted.

The worn pins surfaces and wear debris accumulated during the tests were examined using a scanning electron microscopy and energy dispersive X-Ray spectroscopy to verify dominant wear mechanisms. 


\section{Result and discussion}

3.1. Introducing the Mg-Al-RE alloys for high temperature applications and investigating the reasons of poor mechanical properties of Mg-Al based magnesium alloys at high temperatures

The microstructure of as-cast alloy 1 (AZ91) consists of two phases, a-Mg matrix and $\beta$ $\left(\mathrm{Mg}_{17} \mathrm{Al}_{12}\right)$ intermetallic compound in two kind of morphologies, eutectic $\beta$ and precipitate of $\beta$ due to decreasing of solubility of aluminum with decreasing temperature. According to the binary $\mathrm{Mg}$-Al phase diagram, the composition of AZ91 alloy is close to the hypoeutectic $\mathrm{Mg}-\mathrm{Al}$ alloys and the reason for formation of eutectic phases in a hypoeutectic alloy is the non-equilibrium solidification. By addition of REs as the form of cerium rich misch metal to AZ91 (alloy 1), a rod like $\mathrm{Al}_{11} \mathrm{RE}_{3}$ or $\mathrm{Al}_{4} \mathrm{RE}$ intermetallic phase (the EDS pick of $\mathrm{Al}_{4} \mathrm{RE}$ is like the $\mathrm{Al}_{11} \mathrm{RE}_{3}$ ) [Wang et al., 2003], was observed in the microstructure. More RE addition causes further decrease of $\beta$ phase and coarsening of $\mathrm{Al}_{11} \mathrm{RE}_{3}$ phase in the microstructure. The EDX analysis of $\mathrm{Al}_{11} \mathrm{RE}_{3}$ phases is shown in Fig. 1.
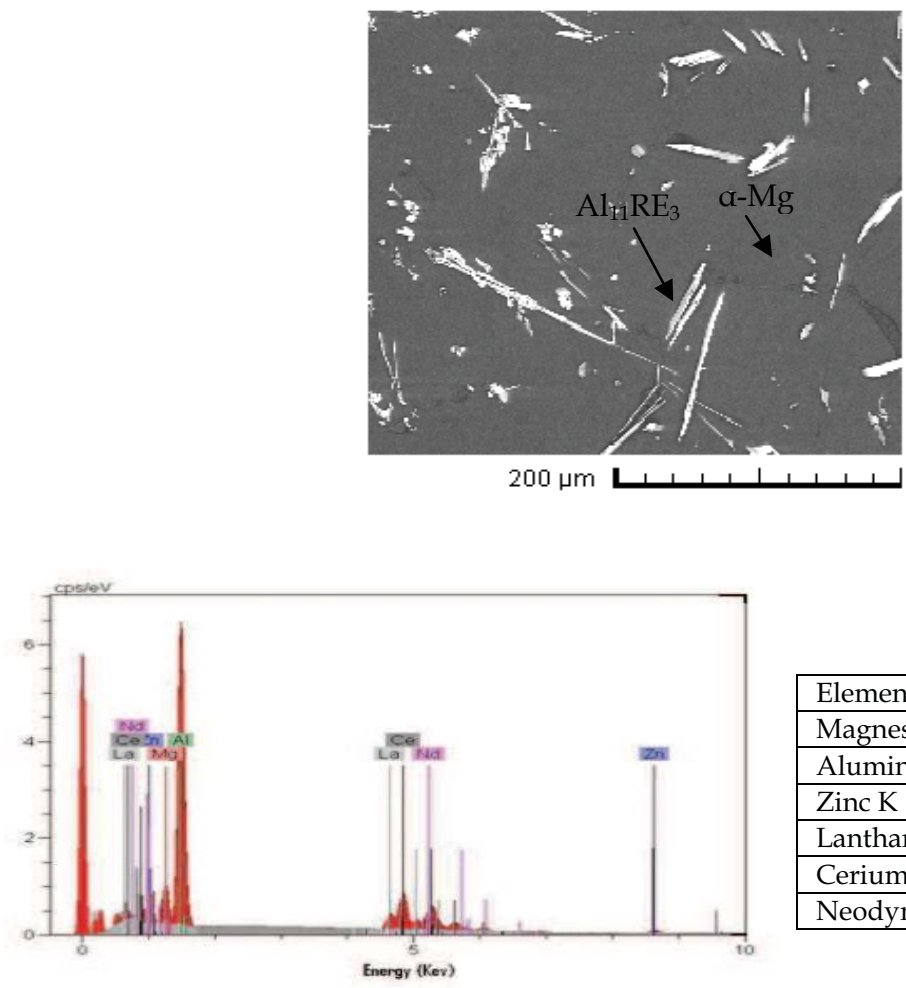

\begin{tabular}{|l|l|}
\hline Element & At. \% \\
\hline Magnesium K & 3.8 \\
\hline Aluminum K & 71.4 \\
\hline Zinc K & 1.7 \\
\hline Lanthanum L & 6.4 \\
\hline Cerium L & 10.8 \\
\hline Neodymium L & 5.9 \\
\hline
\end{tabular}

Fig. 1. $\mathrm{Al}_{11} \mathrm{RE}_{3}$ phase in the microstructure and energy dispersive $\mathrm{X}$-ray analysis of the corresponding particle. 
In the previous works it was observed that AZ91 alloy had poor mechanical properties at elevated temperatures. This was due to the low melting point of the $\beta$ phase which can readily coarsen and soften at elevated temperatures [Moreno et al., 2001; Meshinchi Asl et al., 2010], thus REs were added to $\mathrm{AZ91}$ alloy which result in the formation of $\mathrm{Al}_{11} \mathrm{RE}_{3}$ phase in the microstructure and has a high thermal stability [Khomamizadeh et al., 2005]. The microstructure of alloy 3 (AZ91 $+2 \% \mathrm{RE}$ ) after solution treatment at $420^{\circ} \mathrm{C}$ for $24 \mathrm{~h}$ is shown in Fig. 1. After solution treatment all the $\beta$ particles are dissolved in the matrix due to their low thermal properties but $\mathrm{Al}_{11} \mathrm{RE}_{3}$ needle shape particles remain unchanged due to relatively high melting point of needle shape $\mathrm{Al}_{11} \mathrm{RE}_{3}$ particles.

Fig. 2 shows the tensile properties of specimens tested at ambient and elevated temperatures. The results show that RE addition had little effect on ultimate tensile strength of the alloy at ambient temperature. However the RE addition greatly improved the high temperature tensile strength. This was due to the formation of $\mathrm{Al}_{11} \mathrm{RE}_{3}$ particles which reduced the amount of $\beta$ particles in the matrix and had a relatively high thermal stability.

The most important result caused by RE addition was in creep resistance. Creep tests were performed on specimens over the temperature range of $135^{\circ} \mathrm{C}$ to $200^{\circ} \mathrm{C}$ and at an applied stress of 48-96 MPa. By measuring the slope of the curves, the steady state creep rate of the alloys can be calculated and it is shown in Table 2 for $200^{\circ} \mathrm{C}$. The creep resistance of AZ91 alloy was poor but it can be seen that RE addition resulted in remarkable improvement of creep resistance and the lowest creep rate was obtained for $3 \%$ of RE.

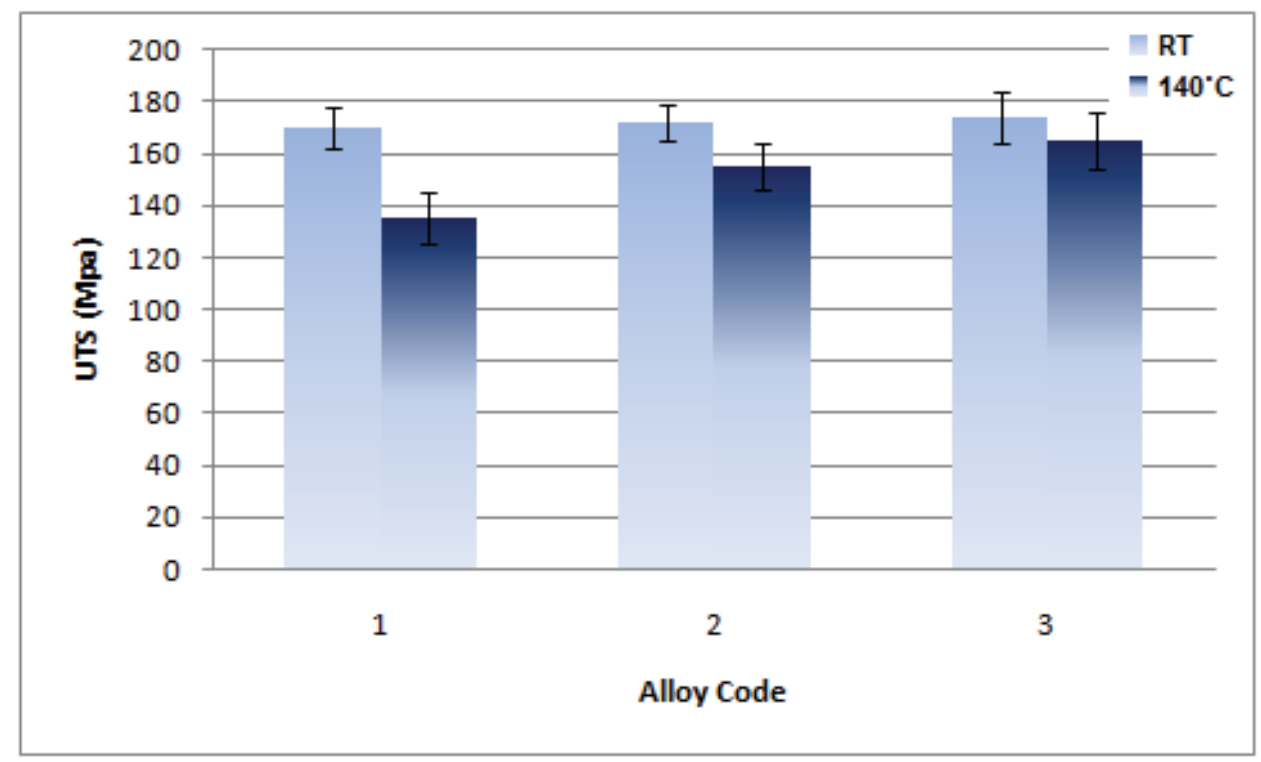

Fig. 2. Mechanical properties of the alloys investigated. 


\begin{tabular}{|c|c|c|c|c|c|}
\hline \multirow{2}{*}{ Alloy Code } & \multicolumn{5}{|c|}{$\underline{\dot{\varepsilon}(1 / \mathrm{sec})}$} \\
\hline & 48 (Mpa) & 58 (Mpa) & 72 (Mpa) & 82 (Mpa) & 96 (Mpa) \\
\hline 1 & $4.2 \times 10^{-7}$ & $8.1 \times 10^{-7}$ & $3.4 \times 10^{-6}$ & $2.1 \times 10^{-5}$ & $6.2 \times 10^{-5}$ \\
\hline 3 & $5.1 \times 10^{-8}$ & $6.8 \times 10^{-8}$ & $1.4 \times 10^{-7}$ & $5.6 \times 10^{-7}$ & $8.2 \times 10^{-7}$ \\
\hline 4 & $3.8 \times 10^{-8}$ & $5.2 \times 10^{-8}$ & $8.7 \times 10^{-8}$ & $3.5 \times 10^{-7}$ & $5.5 \times 10^{-7}$ \\
\hline
\end{tabular}

Table 2. Steady state creep rates of the alloys for different stresses in $200^{\circ} \mathrm{C}$.

The conventional power law equation relating the minimum creep rate, $\dot{\varepsilon}$ min to the applied stress is:

$$
\dot{\varepsilon} \min =A(\sigma / G)^{n} \exp (-Q / R T)
$$

Both $\mathrm{n}$ and $\mathrm{Q}$ are parameters of the material and together may be used to identify the dominant creep mechanism for the material. By plotting logarithmically the minimum creep strain rate versus the applied stress $\sigma$, we can calculate the stress exponent, n. Plot of $\log \varepsilon$. versus 1/T will yield the apparent activation energy, Q [Bettles, 2003; Meshinchi Asl et al., 2009 (b); Somekawa et al., 2005].

The stress exponent $\mathrm{n} \sim 2$ is generally reported for grain boundary sliding, while $n=3 \sim 7$ is for dislocation climb controlled creep, however, high $\mathrm{n}$ values for high stresses often indicate of power law breakdown [Bettles, 2003; Meshinchi Asl et al., 2009 (b)]. The activation energy for self diffusion in magnesium can be taken as $138 \mathrm{~kJ} \mathrm{~mol}^{-1}$. The value of activation energy for boundary diffusion is estimated to be in the range 70-100 kJ mol-1 [Oakley et al., 1995. Meshinchi Asl et al., 2009 (b)]. At low stresses, the stress exponent for as cast AZ91 without REs was found to be 5.7 which is in the range of dislocation climb mechanism. However the activation energy lies between that for self diffusion and grain boundary diffusion, which was measured to be $119 \mathrm{~kJ} \mathrm{~mol}^{-1}$ for the AZ91. Together these two factors may indicate a mixed mode of creep behavior, with some grain boundary effects contributing to the overall behavior. SEM observations performed on specimens also showed a ductile dimple fracture mode of creep rupture for AZ91 alloy in $200^{\circ} \mathrm{C}$ as shown in Fig. 3.

For the AZ91-RE alloy the values of both parameters fit the values for dislocation climb controlled creep. The stress exponent was measured 3.2 and the activation energy was 143

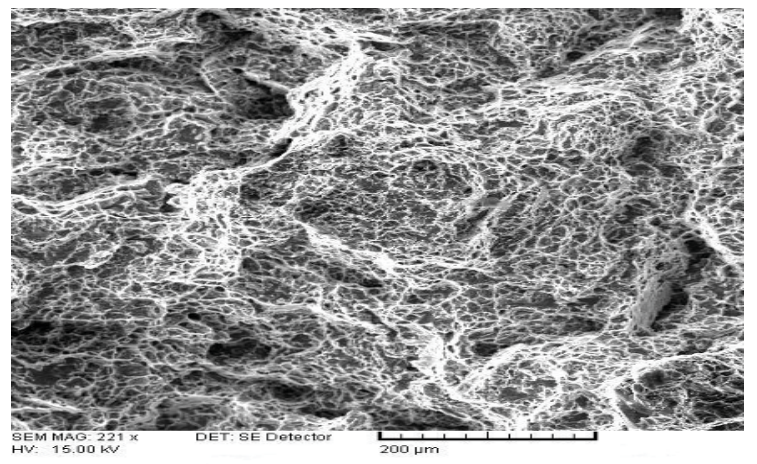

Fig. 3. Fractogragh of alloy 1 at $200^{\circ} \mathrm{C}$ after creep rupture. 
$\mathrm{kJ} \mathrm{mol}^{-1}$. The activation energy is slightly higher that AZ91 alloys without REs which is due to its better creep resistance. The presence of thermally stable $\mathrm{Al}_{11} \mathrm{RE}_{3}$ needle shape particles along grain boundaries pin grain boundaries and hinder both grain boundary migration and sliding during high temperature exposure.

In Mg-Al based alloys, the $\beta$ phase has the most strengthening effect on the alloys at room temperature however it has a low melting point and can readily soften and coarsen with increase of temperature. This is the main factor for poor creep resistance of these alloys and the grain boundaries are weakened because of softening and coarsening of the $\beta$ phase and therefore sliding of grain boundaries has an important part in deformation mechanism at elevated temperatures. By adding $R E s$ the $\mathrm{Al}_{11} \mathrm{RE}_{3}$ needle shape phases along grain boundaries pin grain boundaries and contribute to improvement of creep resistance of the alloys.

\subsection{Effects of aging heat treatment on ambient and high temperature properties of AZ91-RE magnesium alloy}

The AZ91 alloy was heated at $400^{\circ} \mathrm{C}$ for $24 \mathrm{~h}$ followed by water quenching (T4 heat treatment) and then aged at $180^{\circ} \mathrm{C}$ for $20 \mathrm{~h}$ (T6 heat treatment). Fig. 4 shows the microstructure of the

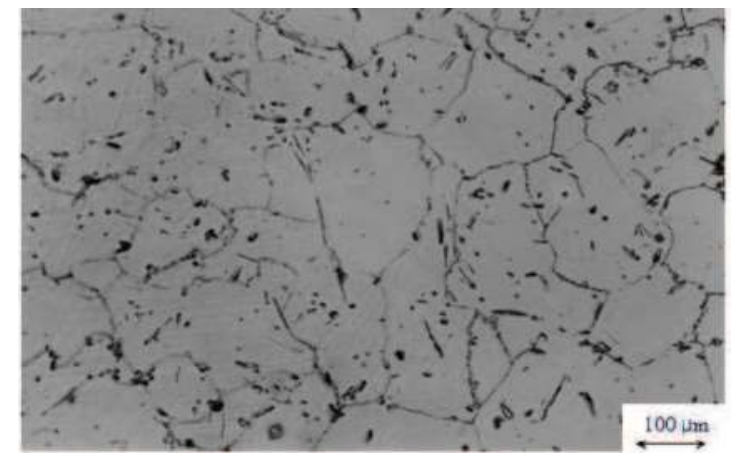

(a)

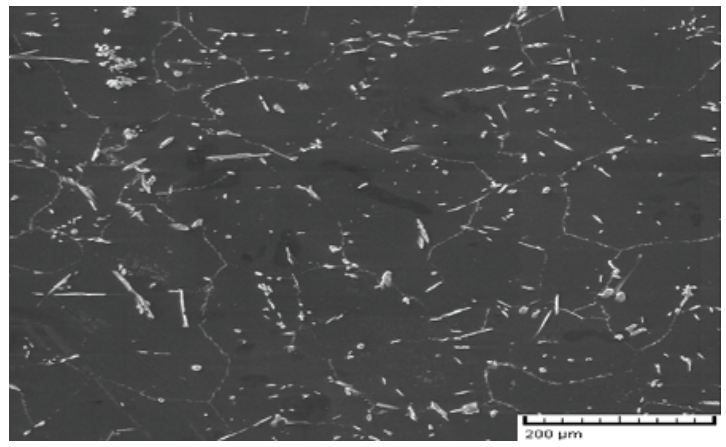

(b)

Fig. 4. Optical (a) and scanning electron microscope (b) image of microstructure of AZ91 $+2 \%$ RE (alloy 3 ) after T4 heat treatment where all the $\beta$ particles are dissolved in the matrix but $\mathrm{Al}_{11} \mathrm{RE}_{3}$ particles remain unchanged after $\mathrm{T} 4$ heat treatment. 
AZ91+2\%RE alloy after T4 heat treatment. All the $\beta$ particles are dissolved in the matrix due to their low thermal properties but $\mathrm{Al}_{11} \mathrm{RE}_{3}$ particles remain unchanged. This is because of relatively high melting point of needle shape $\mathrm{Al}_{11} \mathrm{RE}_{3}$ particles.

X-ray diffraction pattern of AZ91-2\%RE alloy in the form of as-cast and also after T4 solution treatment are presented in Fig. 5. The pattern also indicates that other that a $(\mathrm{Mg})$ and $\beta\left(\mathrm{Mg}_{17} \mathrm{Al}_{12}\right)$ phases which are present in the $\mathrm{AZ91}$ alloy, the $\mathrm{Al}_{11} \mathrm{RE}_{3}$ intermetallic phase is present in the microstructure of the alloy after RE addition. After the solution treatment, the related peaks of $\beta$ phase disappear but the $R E$ containing phase $\left(\mathrm{Al}_{11} \mathrm{RE}_{3}\right)$ still remains in the pattern due to its high thermal stability.
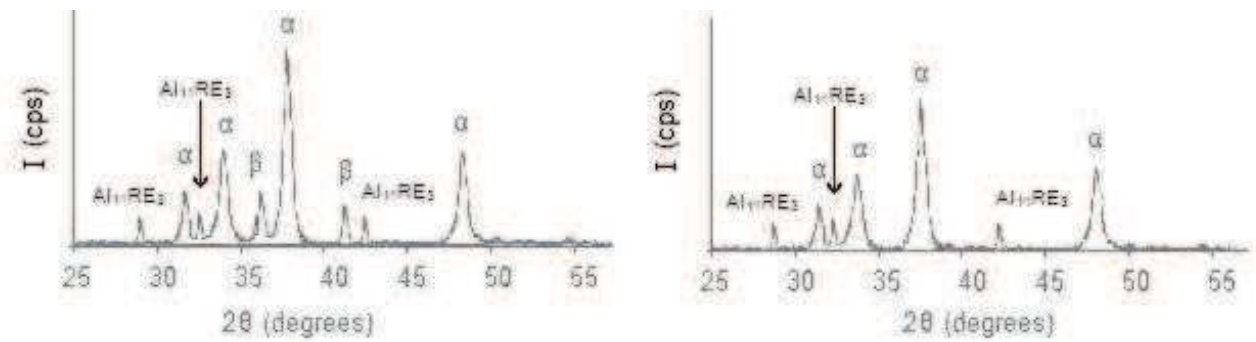

Fig. 5. X-ray Diffraction pattern of AZ91-2\%RE alloy before solution treatment (left) and after solution treatment (right).

For the AZ91 alloy aged at $180^{\circ} \mathrm{C}$ the formation of $\beta$ precipitates occurred in two forms, discontinuous precipitation at the vicinity of grain boundaries (lamellar precipitation) which is dominant and continuous precipitation (fine plate shape precipitates) within grains. Discontinuous precipitation is the cellular growth of alternating layers of $\beta$-phase and nearequilibrium magnesium matrix at high-angle grain boundaries and is the main reason for poor mechanical properties of the alloy at elevated temperatures [Celotto, 2000; Wenwen et al., 2003].

In pure AZ91 alloy, the discontinuous $\beta$ precipitates at grain boundaries are the main reason for poor mechanical properties of the alloy. Fig. 6 shows the fracture surface of AZ91 alloy

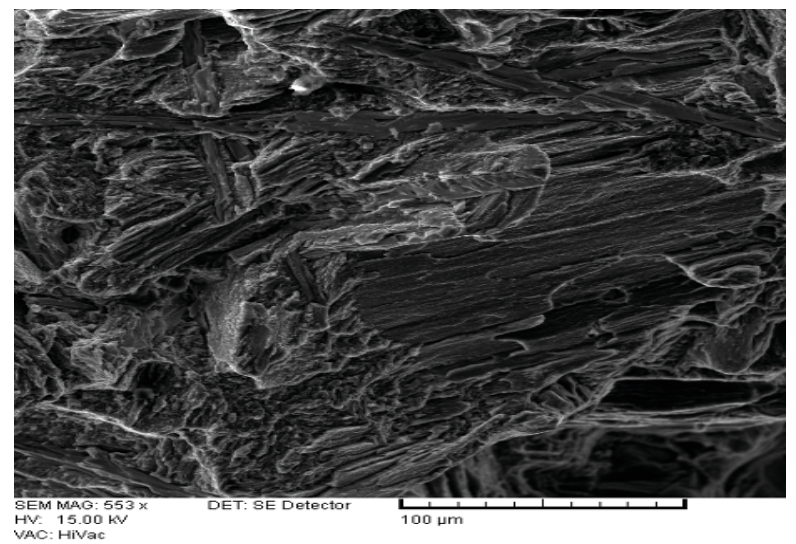

Fig. 6. Fracture surface of AZ91 alloy after the tensile test. 
after the tensile test which is a cleavage kind of fracture. The cleavage facets could be easily seen on the fracture surface.

After the solution treated alloy is aged, the discontinuous precipitations which are dominant at the vicinity of grain boundaries form at early times of aging. Continuous precipitations form at longer times. Fig. 7 and Fig. 8 show the dissolution of $\beta$ particles as the result of solution treatment and then formation of the discontinuous precipitation at grain boundaries after 5 hours of aging. The discontinuous precipitations in $\mathrm{Mg}-\mathrm{Al}$ alloys exhibit different habit planes and morphologies. The most common morphologies of precipitates are long parallel precipitates and bush like precipitates [Dully et al., 1994].

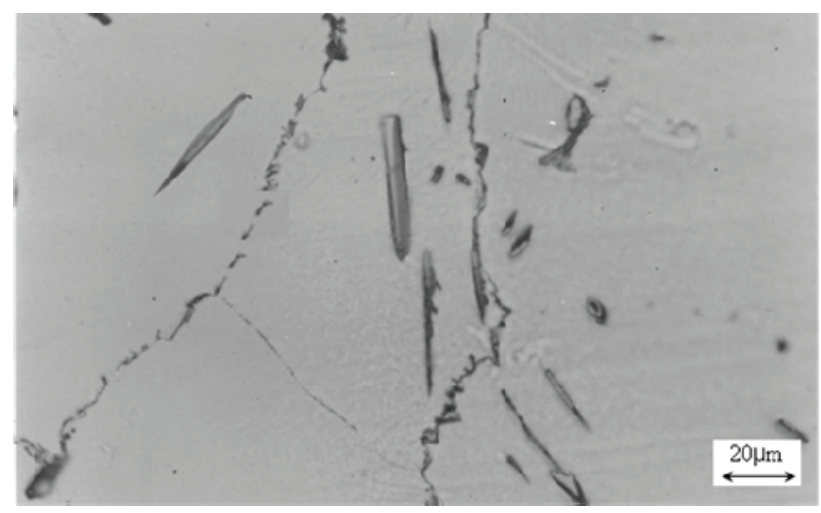

(a)

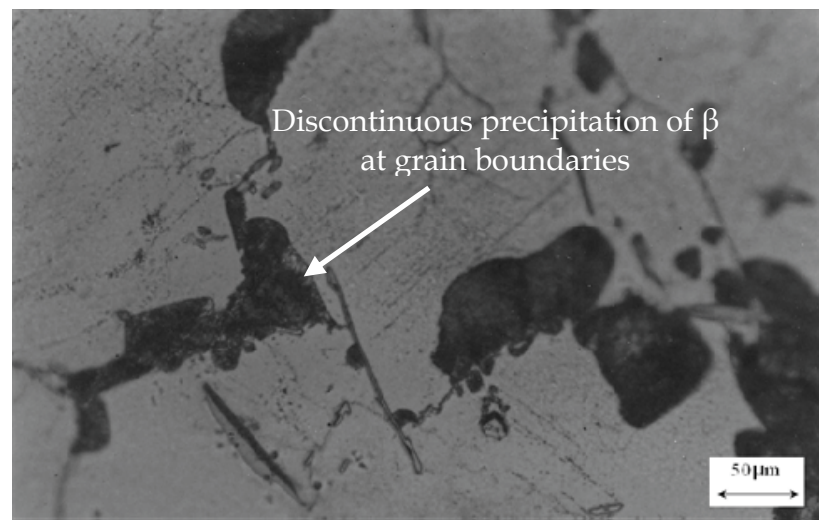

(b)

Fig. 7. Optical microscope image of AZ91+2\%RE (alloy 3) after all the $\beta$ particles are dissolved due to solution treatment (a) and after $5 \mathrm{~h}$ of aging showing discontinuous precipitation at the vicinity of grain boundaries (b). 


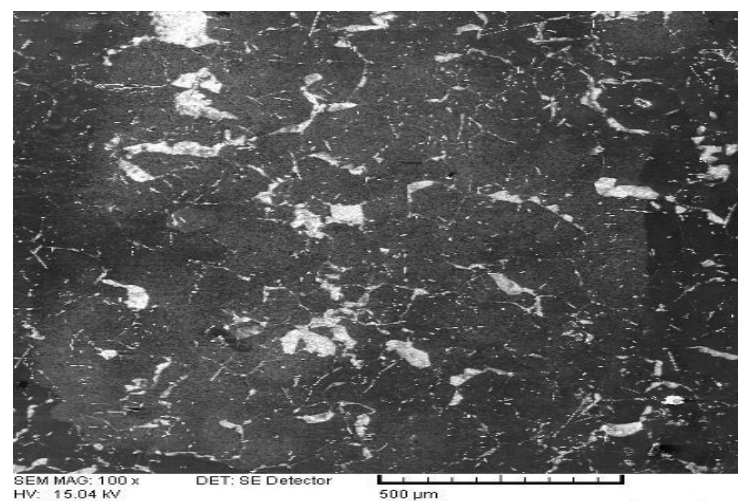

Fig. 8. Scanning electron microscope image of AZ91+2\%RE (alloy 3) after $5 \mathrm{~h}$ of aging.

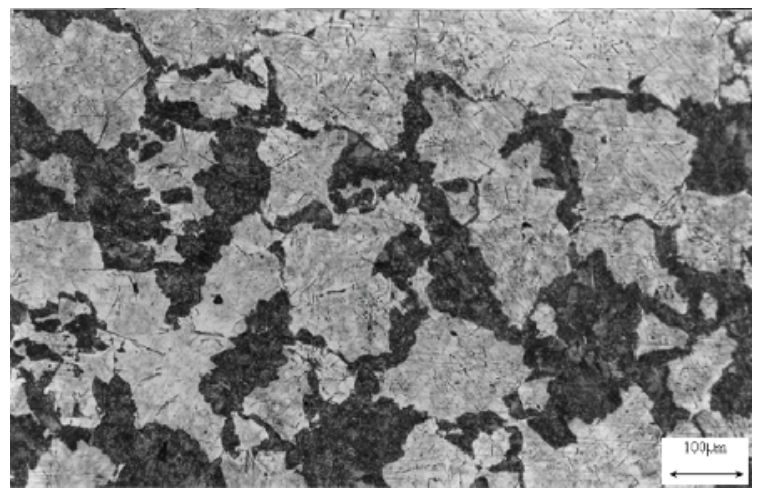

(a)

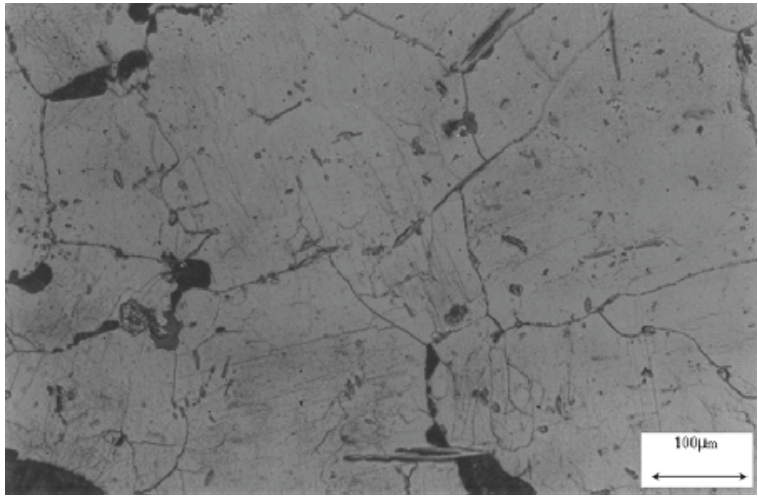

(b)

Fig. 9. Optical microscope image of alloy 2 after all the T6 aging treatment, showing $\beta$ precipitates dominant (a) and alloy 5 after T6 heat treatment (b). 
The discontinuous precipitation of $\beta$ at grain boundaries readily coarsens and softens at elevated temperatures and thus weakens the grain boundaries at elevated temperatures. Therefore sliding of grain boundaries is an important factor in deformation of $\mathrm{Mg}-\mathrm{Al}$ alloys at elevated temperatures.

It could be concluded that RE addition to AZ91 alloy decreases the amount of $\beta$ particles in the microstructure (Fig. 9). After aging the rare earth inclusive alloys, the overall amount of $\beta$ precipitates was greatly reduced and also the discontinuous precipitates were decreased in the microstructure.

Some of the mechanical properties of the alloys tested in this investigation are presented in Table 3. The creep resistance of the pure AZ91 alloy after aging heat treatment was decreased slightly compared to as cast specimens. This is due to the important role of $\beta$ precipitates in the microstructure. While they are the main strengthening effect at room temperatures, the discontinuous precipitates of $\beta$ are mainly distributed at grain boundaries. Their softening and coarsening weakens the grain boundaries at elevated temperatures (Table 4 and Fig. 10).

\begin{tabular}{|c|c|c|c|c|}
\hline \multirow[t]{2}{*}{ Alloy } & \multirow[t]{2}{*}{ Hardness (BHN) } & \multirow{2}{*}{$\begin{array}{c}\text { Yield } \\
\text { strength } \\
\text { (Mpa) }\end{array}$} & UTS (Mpa) & $\begin{array}{c}\text { UTS } \\
\text { (Mpa) }\end{array}$ \\
\hline & & & Room Temp. & $140^{\circ} \mathrm{C}$ \\
\hline AZ91-2\%RE & 63 & 95 & 174 & 165 \\
\hline $\begin{array}{l}\text { AZ91-2\% RE followed by } \\
\text { T4 and T6 treatment }\end{array}$ & 65 & 97 & 179 & 168 \\
\hline
\end{tabular}

Table 3. Mechanical properties of the alloys investigated.

After aging heat treatment of the AZ91 alloy, the discontinuous precipitates of $\beta$ are dominant at grain boundaries and therefore weaken the grain boundaries at elevated temperatures and decrease the creep resistance of the alloy. Thus, despite good mechanical properties of aging heat treatment samples compared to as cast AZ91 alloy for applications at room temperature, these alloys should not be used at application conditions which involve elevated temperatures. By adding REs the metastable $\mathrm{Al}_{11} \mathrm{RE}_{3}$ needle shape phases along grain boundaries pin grain boundaries and contribute to improvement of creep resistance of the alloys.

\begin{tabular}{|c|c|c|c|c|c|}
\hline \multirow{2}{*}{ Alloy Code } & \multicolumn{5}{|c|}{$\underline{\varepsilon}(1 / \mathrm{sec})$} \\
\hline & 48 (Mpa) & 58 (Mpa) & 72 (Mpa) & 82 (Mpa) & 96 (Mpa) \\
\hline 1 & $4.2 \times 10^{-7}$ & $8.1 \times 10^{-7}$ & $3.4 \times 10^{-6}$ & $2.1 \times 10^{-5}$ & $6.2 \times 10^{-5}$ \\
\hline 1 (T4) & $3.5 \times 10^{-7}$ & $6.3 \times 10^{-7}$ & $8.1 \times 10^{-7}$ & $2.9 \times 10^{-6}$ & $5.4 \times 10^{-6}$ \\
\hline 1 (T6) & $7.8 \times 10^{-7}$ & $2.3 \times 10^{-6}$ & $6.5 \times 10^{-6}$ & $5.2 \times 10^{-5}$ & $1.8 \times 10^{-4}$ \\
\hline 3 & $5.1 \times 10^{-8}$ & $6.8 \times 10^{-8}$ & $1.4 \times 10^{-7}$ & $5.6 \times 10^{-7}$ & $8.2 \times 10^{-7}$ \\
\hline 3 (T6) & $3.7 \times 10^{-8}$ & $5.1 \times 10^{-8}$ & $8.7 \times 10^{-8}$ & $1.2 \times 10^{-7}$ & $5.8 \times 10^{-7}$ \\
\hline
\end{tabular}

Table. 4. Steady state creep rates of the alloys for different stresses in $200^{\circ} \mathrm{C}$. 


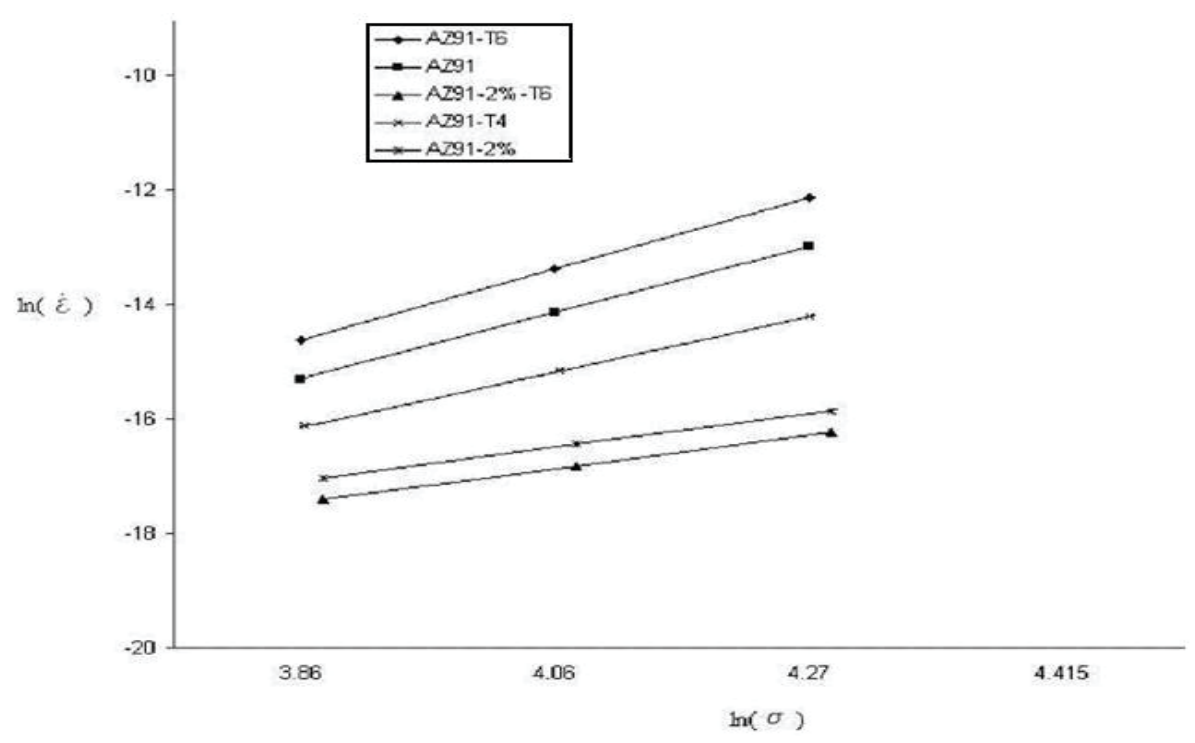

Fig. 10. Variation of creep rate with stress for alloys tested at $200^{\circ} \mathrm{C}$.

\subsection{Wear properties and its influence by Rare Earths addition}

Wear rate under different normal loads for various sliding speeds were measured. The experiments were performed under 10, 20,30, 50 and 100N stationary normal loads and sliding speeds of $0.25,0.5$ and $1.0 \mathrm{~m} / \mathrm{s}$ at various sliding distances from 250 to $2000 \mathrm{~m}$. At constant sliding speed, applying higher normal load increases the wear rate generally. The wear rates increase abruptly at higher loads. The studies indicate that Rare Earth addition to AZ91 had no significant effect at lower sliding speeds. However it influences the wear rate at higher loads and speeds and show superior wear resistance compared with pure AZ91 alloy.

Studies suggest that there are five different operating wear mechanisms: abrasion, dalamination and gross plastic deformation more abundant and oxidation and adhesion less dominant. Abrasion is the prevailing wear mechanism at lower loads. Traces of parallel grooves can be distinguished on surfaces of most samples. These scratches may be attributed to hard asperities of counterface or detached particles that removed from disk or pin and placed in surface contact [Lim et al., 2003; Kumar \& Kumar 2001; Cao et al., 1990].

With the wear process advancement, grooves become wider and deeper. Delamination mode of wear occurred when tests are conducted at sufficient high loads. Higher loads and longer sliding distances play an important role in increasing the probability of crack formation and growth.

High loads at long sliding distances result in severe plastic deformation on materials. As a result, edge cracks are fabricated. Due to intensive frictional heat of wear, AZ91 alloy locally melts and flows in the sliding direction [Chen \& Alpas, 2000; Lim et al., 2003; Lim et al., 2005]. For more information on effect of Rare Earth addition on wear properties of AZ91 alloy, the readers can refer to Meshinchi Asl et al., 2010. 


\subsection{The effect of Al content and Si addition on the high temperature properties of $\mathrm{Mg}$ - Al alloys}

Aluminum is an alloying addition often utilized to improve room temperature tensile properties by solid solution strengthening and precipitation of $\beta$ intermetallic phase. At recent studies it is observed that the beneficial effects of $\mathrm{Al}$ appear to diminish because of microstructural instabilities at elevated temperatures [Moreno et al., 2003], thus alloy 4 was also investigated to compare the effect of reduction of $\mathrm{Al}$ in $\mathrm{Mg}-\mathrm{Al}-\mathrm{RE}$ alloys on microstructural and mechanical properties and creep behavior of these alloys, especially at elevated temperatures.

The RE elements don't have any reaction with magnesium as long as aluminum is in the melt [Khomamizadeh et al., 2005; Meshinchi Asl et al., 2009 (b)]. Thus, Al is consumed in $\mathrm{Al}_{11} \mathrm{RE}_{3}$ particles and the rest of $\mathrm{Al}$ interacts with $\mathrm{Mg}$ and forms the $\beta$ phase. The reduction of $\mathrm{Al}$ in alloy 4 leads to decrease of $\beta$ phase in the microstructure compared with alloy 3.

The addition of Si to AZ91 alloy results in the formation of $\mathrm{Mg}_{2} \mathrm{Si}$ phase (Chinese Script) in the microstructure in addition to the $\mathrm{Mg}_{17} \mathrm{Al}_{12}$ particles. The only microstructural change between alloys with $\mathrm{Si}$ addition is the increase in the amount and size of $\mathrm{Mg}_{2} \mathrm{Si}$ particles. On the other hand because the solid solubility of $\mathrm{Si}$ in $\mathrm{Mg}$ is negligible and $\mathrm{Al}$ and Si don't form any compound, the amount of $\beta$ particles in the microstructure after the addition of Si to AZ91 alloy is constant. Thus, because the microstructre of the alloy after Si addition had no differences in the amount and distribution of $\beta$ particles, the Si does not act as a refiner or modifier for the $\beta$ phase. This behavior is unlike the effect of other alloying elements of AZ91 alloy such as REs which also modify the microstructure and decrease the $\beta$ phase in the microstructure [ $\mathrm{Lu}$ et al., 200]. This is due to the very little solubility between $\mathrm{Al}$ and $\mathrm{Si}$ which results in no changes in quantity of $\beta$ phase after $\mathrm{Si}$ addition

Tensile properties show that alloy 3 with $2 \% \mathrm{RE}$ and $9 \% \mathrm{Al}$ had the best tensile properties at room temperature however at $140^{\circ} \mathrm{C}$ the tensile properties of alloy 4 is better. This is due to the decrease in $\beta$ phases which are the main reason for poor mechanical properties of the AZ91 alloy at high temperatures.

The tensile strength of AZ91 alloy decreases with $\mathrm{Si}$ addition at room temperature. This reduction is due to the formation of brittle $\mathrm{Mg}_{2} \mathrm{Si}$ Chinese Script particles. The amount of $\beta$ phase in alloys with different $\mathrm{Si}$ addition is constant. However, with $\mathrm{Si}$ addition the amount of $\mathrm{Mg}_{2} \mathrm{Si}$ Chinese Script phase increases which leads to a brittle microstructure. Although $\beta$ phase is the most strengthening phase at room temperature in AZ91 alloy, the coarse brittle Chinese Script particles in the microstructure reduce the tensile properties at room temperature.

Creep tests indicate that alloy 4 with 2 weight percent of RE and lower Al content compared to alloy 3 , had a slightly better creep resistance however alloy 3 has a better castability which is also important for industrial applications.

The most important result of $\mathrm{Si}$ addition was the improvement of the creep resistance of AZ91 alloy. Si addition resultes in remarkable improvement of creep resistance and alloy 7 with $1 \%$ of Si had a very lower creep rate compared to alloy 1 . Thus Si addition results in significant increase in creep resistance of $\mathrm{Mg}$-Al alloys.

For the alloy with $1 \mathrm{wt} \% \mathrm{Si}$ addition, the stress exponent was 3.8 and the activation energy was measured $128 \mathrm{~kJ} \mathrm{~mol}^{-1}$. Thus the values of both parameters fit the values for dislocation climb controlled creep. 
The activation energy for alloy 4 is slightly higher than other alloys which is due to its better creep resistance. The presence of thermally stable $\mathrm{Mg}_{2} \mathrm{Si}$ particles along grain boundaries which pin grain boundaries and hinder both grain boundary migration and sliding during high temperature exposure. This will yield to better creep properties in alloys with Si addition. The discontinuous precipitation of $\beta$ are dominant at grain boundaries and weaken the grain boundaries at elevated temperatures. Therefore sliding of grain boundaries is an important factor in deformation of $\mathrm{Mg}-\mathrm{Al}$ alloys at elevated temperatures. For more information the readers can refer to Meshinchi Asl et al., 2009 (a).

\section{Conclusion remarks}

- In AZ91 alloy the creep curves indicate a mixed mode of creep behavior, with some grain boundary effects contributing to the overall behavior. $\beta\left(\mathrm{Mg}_{17} \mathrm{Al}_{12}\right)$ particles usually distributed at grain boundaries, have a low melting point and easily soften at high temperature, resulting in the previously mentioned behaviors.

- Addition of REs to Mg-Al alloys yields to the formation of thermally stable $\mathrm{Al}_{11} \mathrm{RE}_{3}$ needle shape particles which significantly improve creep properties of these alloys.

- $\quad$ The presence of thermally stable $\mathrm{Al}_{11} \mathrm{RE}_{3}$ needle shape particles along grain boundaries pin grain boundaries and hinder both grain boundary migration and sliding during high temperature exposure and therefore increase the creep resistance of the AZ91 alloy. For the AZ91alloy at low stresses, deformation is controlled by a mixed mode of dislocation climb mechanism with some grain boundary effects contributing to the overall behavior. Dislocation climb controlled creep is the dominant creep mechanism for the AZ91-RE alloys.

- $\quad$ Silicon addition to AZ91 alloy forms coarse Chinese Script $\mathrm{Mg}_{2} \mathrm{Si}$ precipitates at the grain boundaries along with $\beta\left(\mathrm{Mg}_{17} \mathrm{Al}_{12}\right)$. The addition of Si to AZ91 alloy doesn't modify the $\beta$ phase morphology and also doesn't change the amount of $\beta$ particles in the microstructure.

- $\quad$ Addition of Si to AZ91 alloy reduces the room tensile properties but improves the creep and elevated temperature tensile properties. After the Si addition, the sliding of grain boundaries is greatly suppressed due to morphological changes.

- $\quad$ The Mg-Al alloy with same RE addition and less Al content had better creep resistance. Thus despite good mechanical properties due to $\mathrm{Al}$ addition at room temperature, the $\mathrm{Al}$ content should be decreased for high temperature applications.

- $\quad$ In the AZ91 alloy, the formation of $\beta$ precipitates occurred in two forms, discontinuous precipitation at the vicinity of grain boundaries (lamellar precipitation) and continuous precipitation (fine plate shape precipitates) within grains. The addition of REs in the form of misch metal (MM) to AZ91 alloy led to formation of needle shape $\mathrm{Al}_{11} \mathrm{RE}_{3}$ particles on the microstructure which have a high thermal stability and improve creep resistance of AZ91 alloy. It also decreases the amount of $\beta$ particles in the microstructure and also decreases the discontinuous formation of precipitates at grain boundaries which have deleterious effect on mechanical properties of $\mathrm{Mg}$ - $\mathrm{Al}$ alloys at elevated temperatures.

- Abrasion, delamination and gross plastic deformation were identified as prevailing wear mechanisms. Abrasive wear activated at lower loads and sliding speeds. It 
increased more wear rates for less ductile specimens of Rare Earth enriched. AZ91 alloy containing Rare Earth content show superior resistance to gross plastic deformation which operated at more severe wear conditions due to existence of $\mathrm{Al}_{11} \mathrm{RE}_{3}$ intermetallic phase which has attractive mechanical properties at elevated temperatures.

\section{Acknowledgments}

The author acknowledges Gary Kaufmann at the School of Materials Science and Engineering of Clemson University for his discussions which were thought provoking and inspiring.

\section{References}

Alahelistan, A. \& Bergamon, F. (1993). Wear 165 (2) 221-226.

Alpas, A.T. \& Zhang, J. (1992). Wear 155 83-104.

Archard, J.F.; (1953). J. of Applied Physics 24 981-988.

Bettles, C.J.; (2003). Materials Science and Engineering A 348 280-288.

Cao, L.; Wang, Y. \& Yao, C.K. (1990). Wear 140 273-277.

Celotto, S.; (2000). Acta Mater. 48 1775-1787.

Chen, H. \& Alpas, A.T. (2000). Wear 246 106-116.

Dully, D.; Cheynet, N.C. \& Bercht, Y. (1994). Acta Metallurgica and Materialia 42 3843-3854.

Gao. X. et al., (2005). Scripta Materialia 53 1321-1326.

Jayamathy, M. et al., (2005). Mater. and Manu. Processes 20(2) 255-271.

Kang, D. H.; Park, S. \& Kim, N. (2005). Materials Science and Engineering A 413-414 555-560.

Khomamizadeh, F.; Nami, B. \& Khoshkhooei, S. (2005). Metallurgical and Materials Transactions A 3489-3494.

Kumar, S. \& Kumar, B. (2001). Wear 247 191-201.

Lim, C.Y.; Lim, S.C. \& Gupta, M. (2003). Wear 255 629-637.

Lim, C.Y.H.; Leo, D.K. \& Ang, J.J.S. (2005).M. Gupta, Wear 259 620-625.

Lu, Y.; (2000). Materials Science and Engineering A 278 66-76.

Mehta, D.S.; Masood, S.H. \& Song, W.Q. (2004). Journal of Materials Processing Technology 155-156 1526-1531.

Meshinchi Asl, K.; Tari, A. \& Khomamizadeh, F. (2009). Materials Science and Engineering A 523 1-6 (a).

Meshinchi Asl, K.; Tari, A. \& Khomamizadeh, F. (2009). Materials Science and Engineering A 523 27-31 (b).

Meshinchi Asl, K.; Masoudi, A. \& Khomamizadeh, F. (2010). Materials Science and Engineering A 527 2027-2035.

Mordike, B.L. \& Ebert, T. (2001). Materials Science and Engineering A 302 37-45.

Moreno, I.P. et al., (2001). Scripta Materialia 45 1423-1429.

Moreno, I.P. et al., (2003). Scripta Materialia 48 1029-1034.

Oakley, R.; Cochrane, R.F. \& Stevens, R. (1995). Key Eng. Mat. 104-107 387-416.

Sharma, S.C.; Anand, B. \& Krishma, M. (2000).Wear 241 33-40.

Sinha, S.K.; Reddy, S.Y. \& Gupta, M. (2006). Tribology Int. 39 184-189. 
Somekawa, H. et al., (2005). Materials Science and Engineering A 407 53-61.

Spigarelli, S.; (2000). Scripta mater. 42 397-402.

Wang, Y.; Wang, Q. \& Ma, C. (2003). Materials Science and Engineering, A 342 178-182.

Wenwen, D. et al., (2003). Materials Science and Engineering A 356 1-7. 


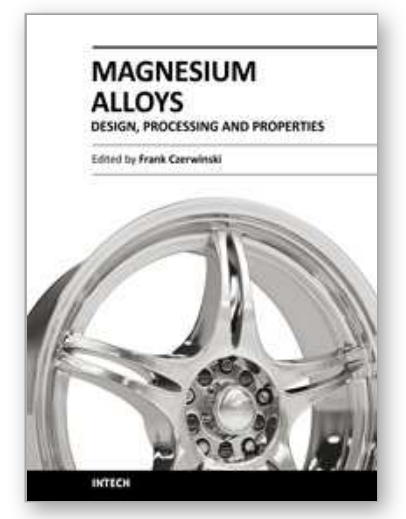

\author{
Magnesium Alloys - Design, Processing and Properties \\ Edited by Frank Czerwinski
}

ISBN 978-953-307-520-4

Hard cover, 526 pages

Publisher InTech

Published online 14, January, 2011

Published in print edition January, 2011

Scientists and engineers for decades searched to utilize magnesium, known of its low density, for lightweighting in many industrial sectors. This book provides a broad review of recent global developments in theory and practice of modern magnesium alloys. It covers fundamental aspects of alloy strengthening, recrystallization, details of microstructure and a unique role of grain refinement. The theory is linked with elements of alloy design and specific properties, including fatigue and creep resistance. Also technologies of alloy formation and processing, such as sheet rolling, semi-solid forming, welding and joining are considered. An opportunity of creation the metal matrix composite based on magnesium matrix is described along with carbon nanotubes as an effective reinforcement. A mixture of science and technology makes this book very useful for professionals from academia and industry.

\title{
How to reference
}

In order to correctly reference this scholarly work, feel free to copy and paste the following:

Kaveh Meshinchi Asl (2011). Improving the Properties of Magnesium Alloys for High Temperature Applications, Magnesium Alloys - Design, Processing and Properties, Frank Czerwinski (Ed.), ISBN: 978-953307-520-4, InTech, Available from: http://www.intechopen.com/books/magnesium-alloys-design-processingand-properties/improving-the-properties-of-magnesium-alloys-for-high-temperature-applications

\section{INTECH}

open science | open minds

\author{
InTech Europe \\ University Campus STeP Ri \\ Slavka Krautzeka 83/A \\ 51000 Rijeka, Croatia \\ Phone: +385 (51) 770447 \\ Fax: +385 (51) 686166 \\ www.intechopen.com
}

\author{
InTech China \\ Unit 405, Office Block, Hotel Equatorial Shanghai \\ No.65, Yan An Road (West), Shanghai, 200040, China \\ 中国上海市延安西路65号上海国际贵都大饭店办公楼405单元 \\ Phone: +86-21-62489820 \\ Fax: +86-21-62489821
}


(C) 2011 The Author(s). Licensee IntechOpen. This chapter is distributed under the terms of the Creative Commons Attribution-NonCommercialShareAlike-3.0 License, which permits use, distribution and reproduction for non-commercial purposes, provided the original is properly cited and derivative works building on this content are distributed under the same license. 